ISSN 1112-9867

\title{
DESIGNING REMOTE WEB-BASED MECHANICAL-VOLUMETRIC FLOW METER READING SYSTEMS BASED ON RENEWABLE ENERGIES
}

\author{
R. Barmeh Ziar
}

Electrical engineer of Lorestan Water and Wastewater Company, Lorestan, Iran

Published online: 15 May 2016

\begin{abstract}
Today, in water and wastewater industry a lot of mechanical-volumetric flow meters are used for the navigation of the produced water and the data of these flow meters, due to use in a wide geographical range, is done physically and by in person presence. All this makes reading the data costly and, in some cases, due to the rugged topography, there is no possibility to get the data at a specific period. Since water and wastewater companies produce water and knowing the amount of water produced is one of the important components in short and long-term planning, the purpose of this project is obtaining the data from mechanical counter meters and sending data online over the Internet. The project challenges include the lack of electricity in the installation place of water meters, the existence of mechanical counters, and the quality of sending data to the web-based central server. The reasons to work on these flow meters are the high number of meters in the country, about 3.5 million meters, which makes the project economically justifiable, low price of mechanical-volumetric meters compared to ultrasonic and magnetic ones, domestic production of these meters, and convenience after-sales service in supplying components, and acceptable accuracy. Replacing these meters with similar ultrasonic and magnetic ones imposes a lot of costs to water and wastewater companies, which is inaccessible according to their current budgets.
\end{abstract}

Author Correspondence, e-mail: brezvan @ yahoo.com

doi: http://dx.doi.org/10.4314/jfas.v8i3s.167 
Conducting this project empowers water and wastewater companies in efficient use of resources, so that in this project once a sudden increase in consumption is spotted an alarm goes off in web based software, announcing the possible fractures in transmission lines and prevents water loss and other damage and also provides the ability to control and manage consumption. In this project, it is planned so that by using renewable energy sources, electricity needed for the device is supplied, and the existing infrastructure of the telecommunications is used in data transmission.

Key words: mechanical meter; readrealay sensor; ARM; RTU;and GSM microcontroller.

\section{INTRODUCTION}

Water loss in water networks in a mechanical and non-physical way that may flow out of storage tanks and pipe of the network of water distribution and sub-branch of the customers, which may flow as leaking or burst of primary and secondary pipes network of branches and valves out of the water distribution system wastes huge amount of clean water that is refined with many problems in some villages, and wastewater companies incur huge costs. Moreover, in our country, in addition to the economic costs imposed to the government in this regard, our country has limited water resources, and in most cases, $60-40 \%$ of the water produced for drinking in rural areas is wasted as losses that are extremely high.

Therefore, identification of water losses and providing ways of coping with it pose many problems to the country's water and wastewater sector.

\section{RESEARCH METHOD}

This process consists of five parts:
A) Data harvesting from mechanical counters meters in various models
B) Registration of the produced data by meters to monitor information and planning at different time intervals
C) Sending and receiving data remotely without having to visit the place
D) Local control and control processes on consumption and alarming by the device
E) Software with technical and managerial capabilities
To measure fluid flow from a closed route (like pipelines) or open routes (like canal) with certain profile various equipment can be used. In some of these devices, fluid volume flow is directly read and in some other cases after measuring the discharge, flow rate of fluid volume has been 
estimated with good approximation. According to standard definition (Zappe, RW, 1971) OIML R49-1: 2006, water flow meter is a device for continuous measurement and preserving the volume of water passing from one path. According to this definition, the component units of the flow meter can be divided into three main sections:

- Measuring section

- The counter

- Display

Measuring section of the meter that has the task of converting volume, flow, speed, or weight of the water passing to signs or signals to be counted. These signals are transmitted mechanically or electronically to the counter section and after counting and processing and the results are read from display section.

Each of the above sections can be places in separate capsules or all three are placed in the same place. In general, according to the style and type of measurement mechanisms, types of meters can be grouped into four main groups according to Table 1 (Clarket et al.,1971)

Table 1. Types of meters

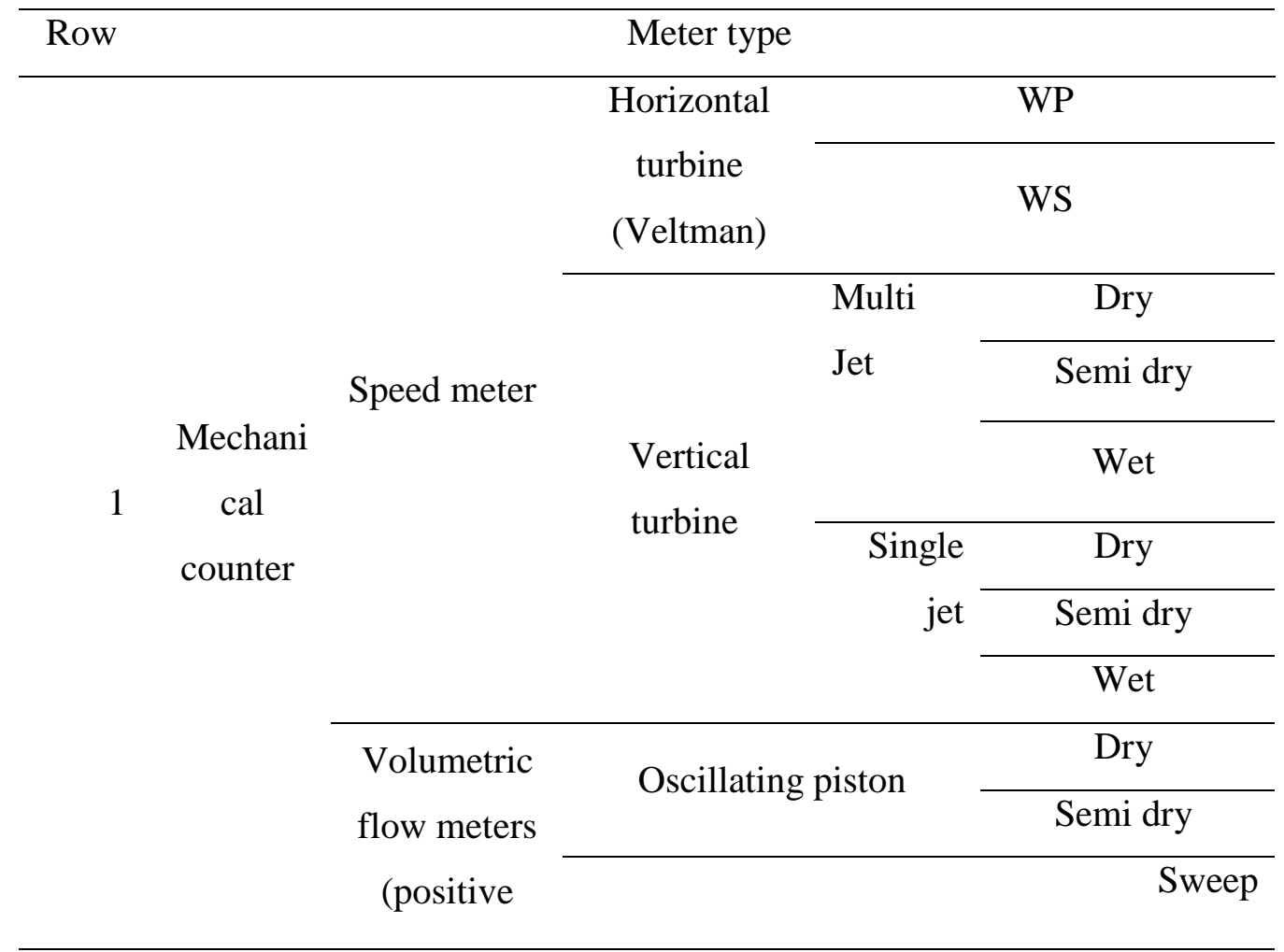




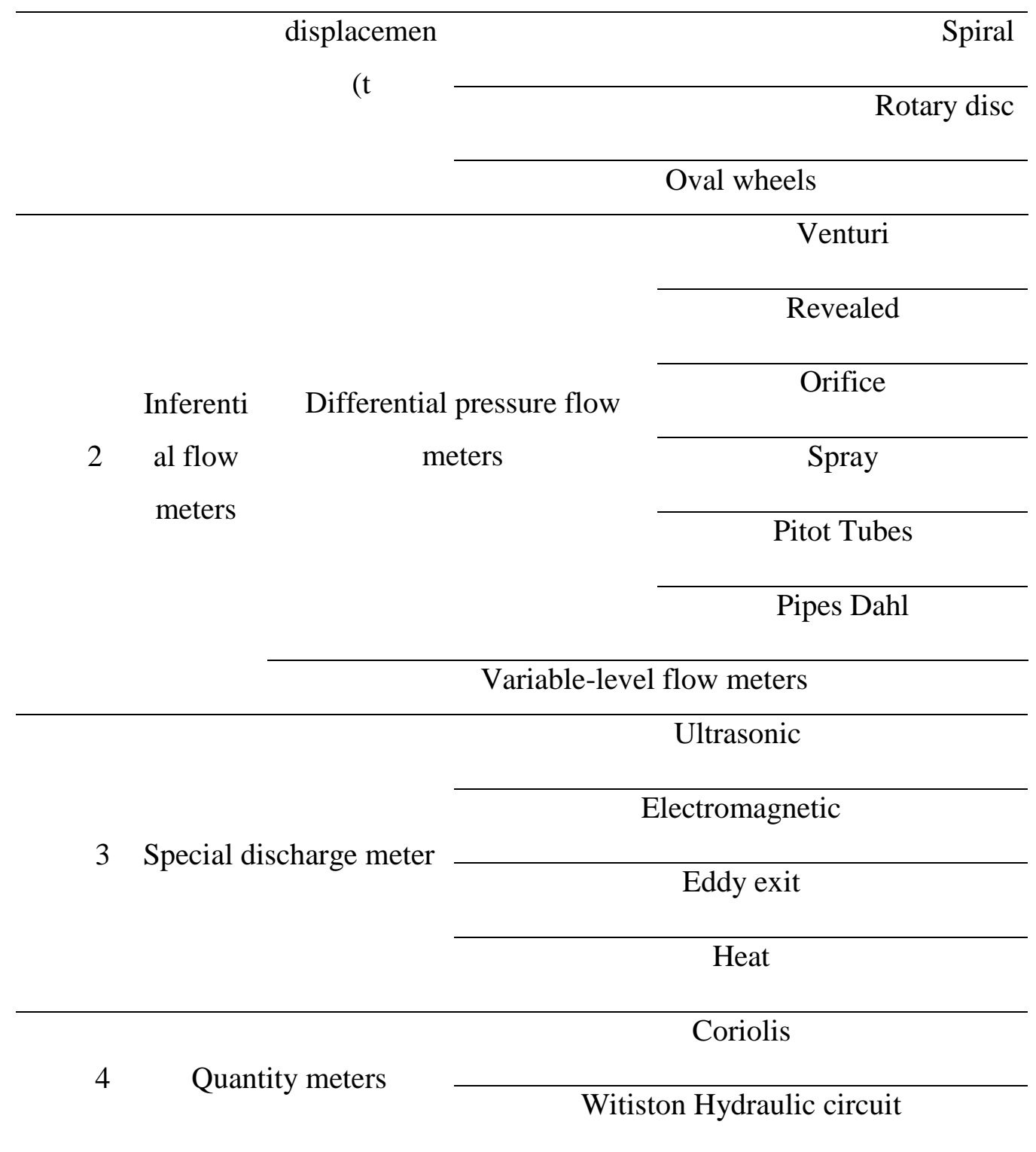

\section{MECHANICAL METERS}

One of the most popular type of meters for direct measurement of consumed water volume and the product of major meter producing corporations in the world is mechanical meters.

In these meters, a flow-detecting component like a propeller or moving piston whose movement volume is in accordance with the movement of the fluid and with the transmission of the fluid through this piece, the consumed amount of water through central axis of the meter is measured (Sanks, 1989). 
The transmission of movement of the propeller to the counter is possible through gear wheel (Gearbox type) and in a mixture type of the involvement of two permanent magnets and some gears (magnetic type).

In gearbox type meters, if all internal parts are in contact with water, it is called wet type, if except the counter section, other part in contact with water, it is semi-dry, and if just the propeller is in contact with water (such as magnetic meters), it is called dry type.

In semi-arid meters, if totalizer is encapsulated in an isolated capsule and contains the solution, it is called Liquid filled (Arora, 1978).

The advantage of magnetic meters compared to gearbox meters is the reduction of internal parts contact with water, precipitation, preventing it from damage caused by jam of meter internal parts. However, cases such as the effect of external magnetic fields on the meter performance, occurrence of disconnect of the permanent magnets, and attracting probable metal filings present in the water are the disadvantages of these type flow meters. Many prestigious meter firms have solved the above-mentioned problems by principled designing and building an anti-magnetic ring and the use of permanent proper magnets in its products.

\section{The size of the meter}

The meaning of meter size is the size of the mouth of the passage of water that is expressed based on millimeter and the British system in inches. Usually mechanical meter, with size less than $50 \mathrm{~mm}$ ( 2 inches) that is mostly installed in sub lines and branches are known as small sized or in-house 11 meters, and meters with a size greater than $50 \mathrm{~mm}$ ( 2 inches), which are used in major water pipelines known as large sized meters or voluminous 12.

By considering hydraulic issues, it can be said that the size of the meter to some extent represents the range of its working capacity as well. This means that for a mechanical meter with $25 \mathrm{~mm}$ size (one inch), maximum allowable discharge is defined up to $7 \mathrm{~m}^{3} / \mathrm{hr}$. that is the use it at maximum capacity or above may be interfered meter operating system (Spitzer, 1990). 


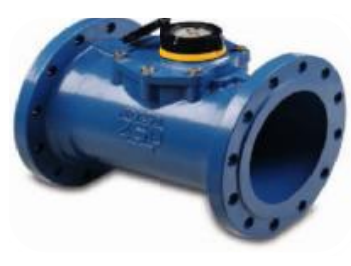

B

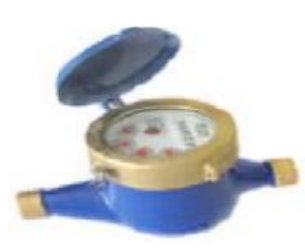

A

Fig.1. A- (low size meter), home-use B- (large size meter) large

\section{Remote mechanical meter reading systems}

Nowadays, a lot of progress is made in making all kinds of water meters, of which the new generation of mechanical meters with remote reading capabilities can be mentioned. These meters, whose use is growing in urban water supply, are designed in a way that in addition to the normal performance and allowing normal operation of them and have the ability to install auxiliary equipment of remote reading this equipment so that with the help of this device, one can measure their use from distance.

Although the use of remote reading systems requires greater investment than conventional meters, the following features are of the reasons of tendency to these systems:

- Speed in meter reading and no need to direct reference

- The momentary control of the meters functions

- Increasing social security and lack of reference of people to the privacy of subscribers

- The possibility of isolation meters and as a result lack of manipulation by various individuals

Remote meter reading system in new mechanical meters depending on equipment can have different performance, of which the possibility of meter reading from a screen mounted behind the door, or reading it with the help of radio waves from the moving car or reading the meter by phone from the meter place can be noted.

In general, remote meter reading system equipment can be classified into three main parts:

1. Transferor of information

2. Information receptor

3. Information processor 


\section{Transferor of information}

This includes an optical or magnetic sensor, which is connected to the counter by a special cable connected to an electrical component that has data storage ability (Fig. 2). The mentioned electronic device can be installed and used at distances away from the meter.
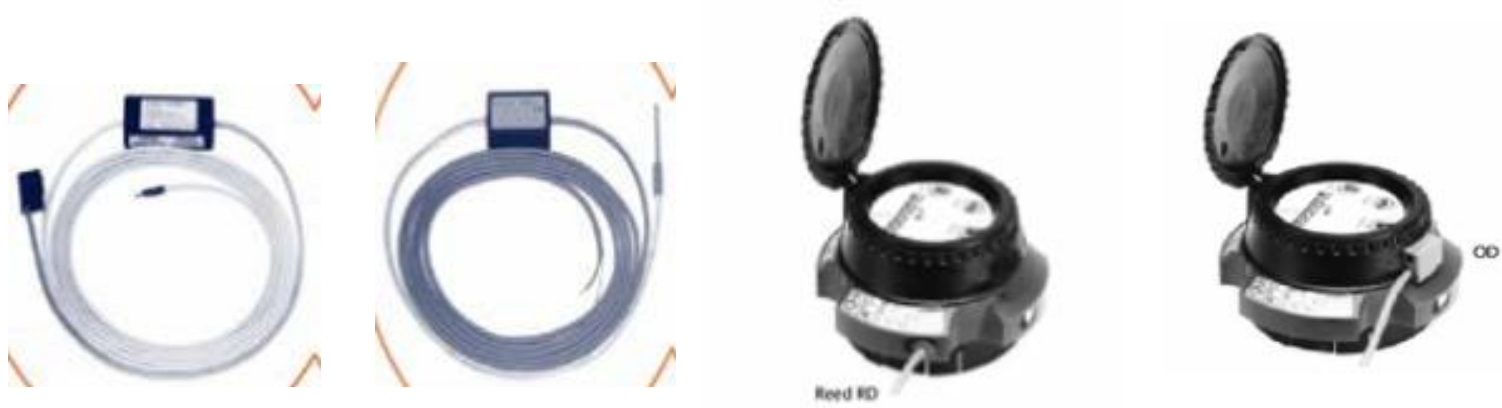

Fig.2.

Examples of optical and magnetic sensors and counters transmitter of information collection, known as the pulser 8 meters is produced by different companies and in different types and with different supply efficiency, which can include the following items:

- Pulser with the ability of keeping and showing data from a meter

- Pulser with the ability of keeping and showing simultaneous information from several meters

- Pulser with the ability to transmit information with the help of radio waves

- Pulser with the ability to connect to the modem to transmit information via telephone

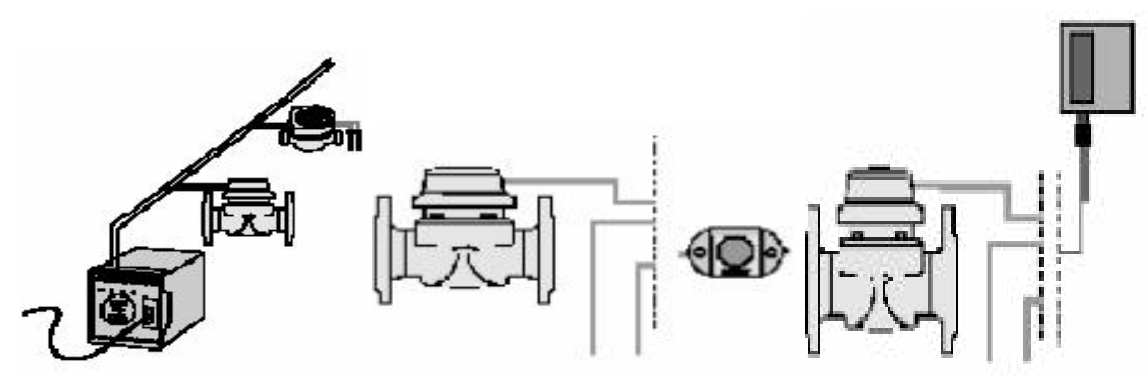

Fig.3. Pulser system with one-meter 


\section{Information receptor}

This includes portable electronic equipment used by meter developers to get the data stored in the pulser. Information receptor part consists of two main parts to obtain and store information, which are connected together by a special cable. Receiver unit can be divided into two types of calls (for pulsers of transmission of information via direct contact) and radio (for pulsers to transmit information using radio waves).

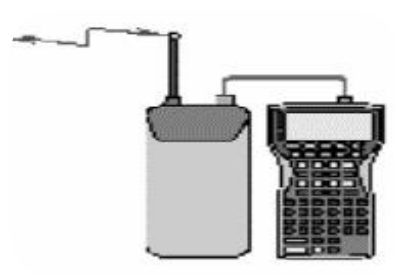

radio method

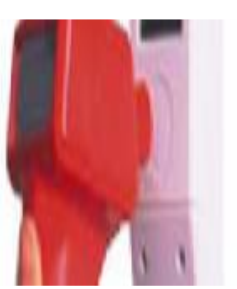

call method

Fig.4. Methods of obtaining information

Information storage unit is like a calculator with high storage memory similar that can sustain a large number of meter's data. The entry of data to this unit is possible both from the receiver unit connected to it and through hand by flow meter writer. If you in an area all meters are equipped with radio-transmit pulsers, with the help of radio receptor system automatically during motion meter data could be entered into the storage unit. If the meter is equipped with a telephone pulser, the possibility of transferring information over the phone will be possible. Meanwhile, with the help of information collection unit, meter man will be able to change measurement units or if needed zero the meter number.

\section{The data processor:}

In fact, it is special software installed on computers that by connection of information storage unit into the computer, information-processing operations such as determining consumption, calculating the amount of water prices, changes in tariff and so on are done.

\section{Remote meter reading capability}

Meter reading capability in digital meter is done in two methods: magnetic or optical. Magnetic method is mostly used in meters with pulse sensor and data is transferred by wire connected to the meter to store data. 
An optical method is mostly used for meters that have optical sensor and data storage unit with the capability of radio data transmission is installed onto the meter. In this method, data receiving device can be at a distance farther than the meter.

Both methods are usually used on dry magnetic meters. Mechanical meters do not have the ability to get the data and the user of this meter should be present at installation place and take action to get the information of the meter. Due to wide geographical dispersion of areas, and sometimes hard access to places, the ability to access the data is hardly possible and lack of timely notice of the volume of water production makes management and planning resources to provide drinking water nearly impossible. Given the widespread use of mechanical volumetric meters in a wide range, and impossibility to replace them with digital meters, due to high costs, and lack of fiscal resources that the government faces, we were made to offer a suitable and low cost solution.

One of the major problems in this project is harvesting data from different meters and in fact changing mechanical meters to counters with capabilities similar to that of digital meters, in the image below, an example of these meters is given.

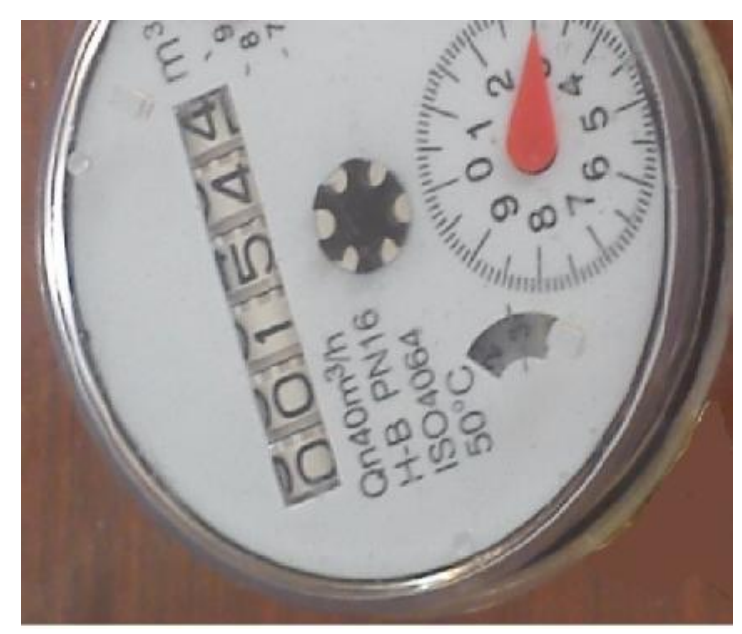

Fig.5.

In Figure 5, it is shown that this meter is mechanical and has no digital output: of this type about a hundred and twenty thousand units are installed in the entire country, which is a good record, and turning this meter into a meter with digital output is a key part of the project. In all these counters, there is a rotating part, which gets the force to turn from collision of water with the 
blades engaged in the lower part of the flow meter and their main idea is to use a magnet in one of the rotating parts.

In this study, an elegant magnet was put on the gear and on the facing part, using a magnetosensitive switch, whenever the mounted rotary magnet passes in front of the sensor; it changes this sensor from the disconnected state into connected state NC to NO. Thus, we succeeded, to get a square pulse output from the rotation of this meter time of the meter. This pulse gives an ARM microcontroller to the entry of the meter so that the counting is done. The number produced by mechanical meter is equal to digital counter and by counting pulses in seconds and minutes and hours, can obtain liters per second and cubic meters per hour. The sensor used has the features of Figure 6:

SPST read switoh

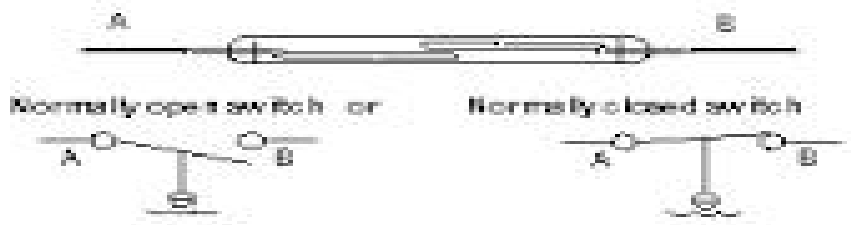

SPDT read switoh

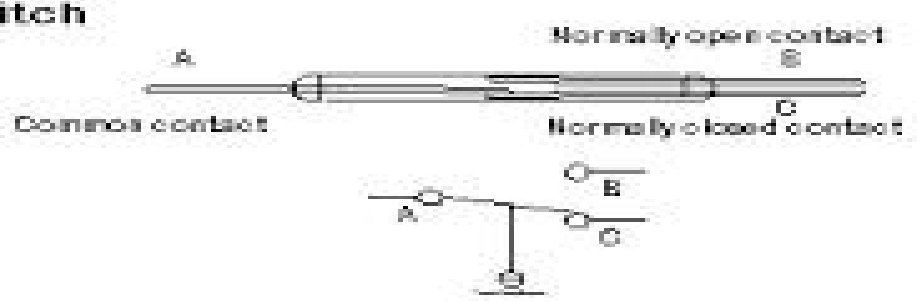

Fig.6.

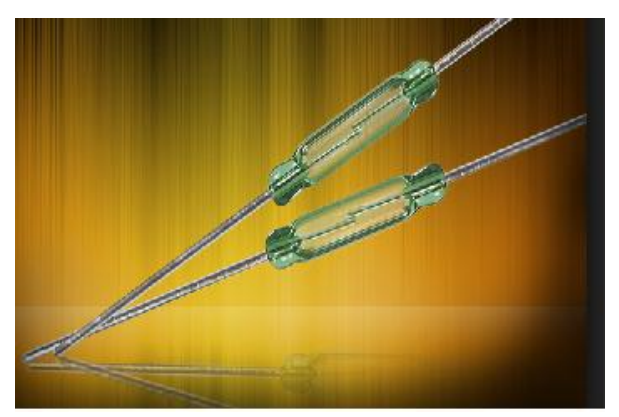

Fig.7. Reed relay sensor 
This sensor is installed in the lower part of the meter, so that meter can be used in its previous location. In three-dimensional designing, it was acted in a way that, the sensors are easily placed in the empty spaces of the meters and there is no need to be replaced, like Figure 8.

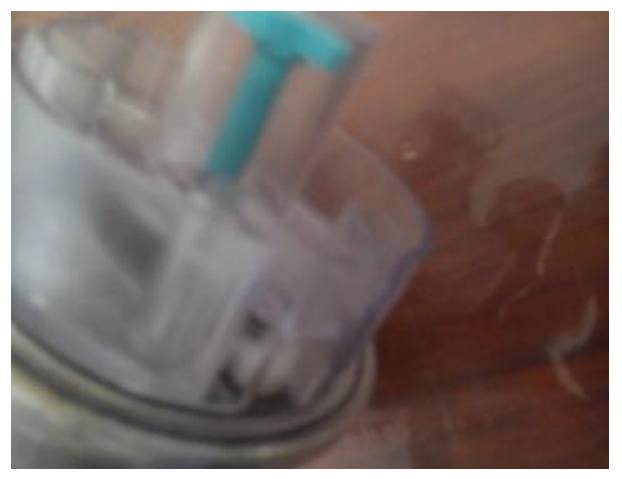

Fig.8.

In Figure 9, the samples of reed relay sensor that is placed inside the mold for sensors is seen.

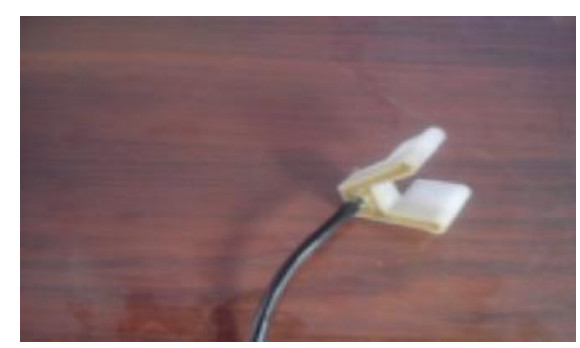

Fig.9.

In the next part, sensor output was connected to ARM microcontroller, and the obtained data from the sensor that is in a square pulse is read and shown on the screen. In this case, the number of mechanical meters is equal to the shown number and the output changes to GSM module by ARM microcontroller to send the data to send the data to the target server hardware shown in Figure 10: 


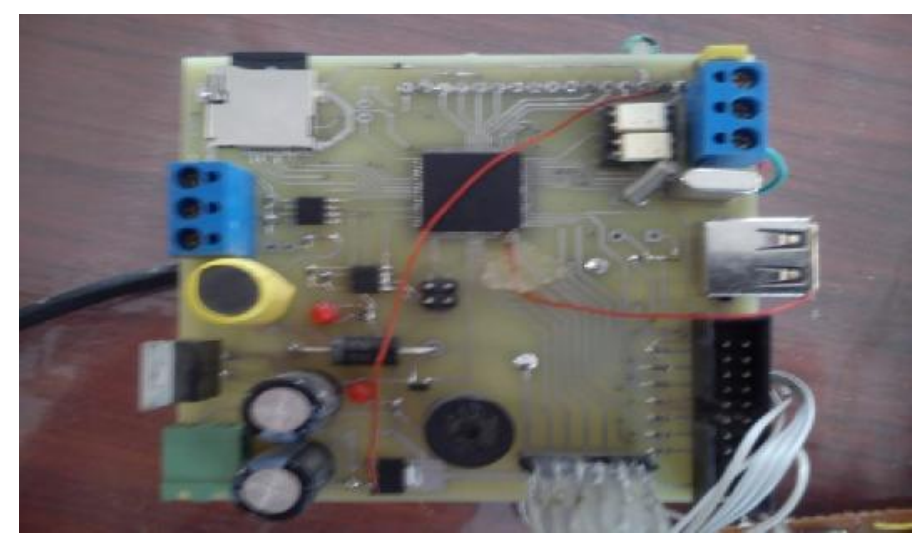

Fig.10.

As shown in Figure 10, in this hardware, there is the capability to store data so that in case of non-connection of the modem, data from the meters does not gone away and is usable. In Figure 11 , the sample meter attached to the digital meter is shown.

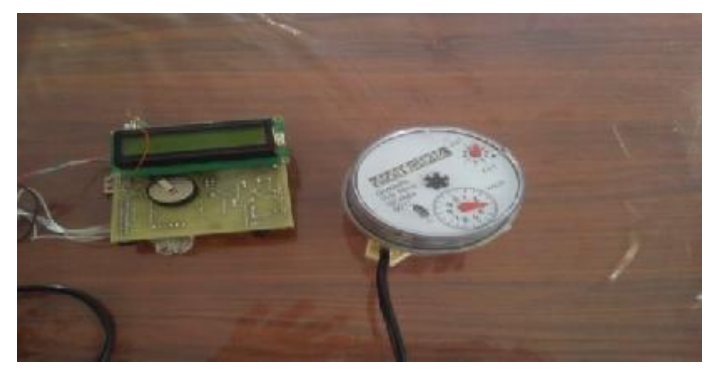

\section{Fig.11.}

To preserve system data, backup battery is used, so that this backup battery can easily retain the produced data for thirty days and show it when connected to power. In this project, the information is stored in configurable intervals on SD cards and can be obtained by USB ports. In this project, ARM microcontroller is used as the main processor and all processes associated with the sensor input and output of the meter, the related calculations, and communication with GSM modem and the serial port connection with the Memory Stick SD CARD are done through the microcontroller. In this project, we have tried to use a strong microcontroller so that all the processing is done fast. 
Hardware used has a digital input to connect to the meter sensor and an RS 485 output for connecting with the modem.

\section{Different parts of the monitoring system}

\section{Hardware}

This part is responsible for collecting all the information of pumping stations including tank level, water quality and quantity parameters, data switchboard, security systems, etc. to send to dispatching center.

\section{The software}

In this part, the system records the sent information from processing information transmitted from each station, and in case of any error, it is graphically displayed in the control room. Software installed in the dispatching room allows us to control and monitor all the pumping stations.

\section{Principles and criteria of designing telemetry equipment}

Wireless telemetry is today known throughout the world as a powerful instrument to collect and store information. This branch of engineering is used as an important tool to manage the accurate and timely predictions for flood control, drought, and planning for sustainable development in the life cycle of the studied areas. To select the best telemetry and remote control systems, environmental and regional conditions and the following key factors should be considered (Barmeh Ziar, 2011).

In short, in the design and construction of a telemetry network, many technical factors and numerous equipment are involved a short list of them includes (Barmeh Ziar, 2011):

- Measurement sensors

- $\quad$ RTU (Remote Terminal Unit)

- Communications equipment in each station (Communication Devices) and their communication protocols

- Collection and processing information tools at the central station (SCADA Center)

RTU has the task of gathering information from the sensors and bringing them to a suitable form for use by telecommunications protocols and transfer to telecommunication base. Each RTU gets the required information through communication either with electrical signals or through serial gates of smart equipment. Communication protocol is the language used to receive and transmit information on the net 


\section{The study of telecommunications networks:}

Telecommunication network refers to telecommunication equipment that sends analog information collected from the control to the central control room sent and vice versa transfers commands issued from the central control system to control points (Barmeh Ziar, 2011).

Each type of telecommunication technologies has their own advantages and disadvantages making them proper for a particular application, and not for the other, drawn undesirable. Varieties of telecommunications networks for this project include the following:

- Radio system

- Cable

- Satellite

\section{Checking communication techniques}

Telephone lines

$>$ GSM network

$>$ Radio VHF / UHF

$>$ Transmission via satellite

\section{Phone lines}

Telephone lines, due to the low price and availability, almost all urban areas and many rural areas, are a cheap method of data transfer. Of the disadvantages of this method, one can refer to low reliability and low relatively bandwidth and noise in the transmission of Information, so that in critical applications network intercept is reduced to the minimum amount. This method does not have the necessary stability. It should be noted that, today, with special modems, there is the possibility of transmitting data up to 56 kilobits per second by public telephone lines.

\section{GSM network}

Mobile, because of a pre-built network structure, and due to low production of data and lack of need to send and receive high data rate, is used as method of data transfer.

Now, in many developed countries of the world, GSM network is used as a reliable medium to convey information. Another highly reliable communication medium that is used in the leading countries in the field of telecommunications is GPRS network that is based on GSM-established context, which send data up rate of $50 \mathrm{~kb} / \mathrm{s}$. In our country, unfortunately, this communication platform is not being used enough. 


\section{VHF/UHF Radio networks}

Radio channel on frequency band of VHF or UHF, in case of good visibility, accurate local site, and installation of telecommunication towers in the right locations, can be used with high reliability to send information. Of the other advantages of this method is permanent and reliable transfer of information, using a private radio network to the center and being available. Of the disadvantages of this method is the need for direct vision for the antennas and if there is a natural barrier on the track, radio repetitions should be used. The biggest advantage of this method is no need to get a permit from the relevant organizations.

\section{The proposed radio system}

Development capabilities of radio remote meter reading system should be considered in the initial installation. Systems designed with the radio repeater equipment have many advantages because by just installing one radio in one point and a radio antenna in the desired direction, we can increase the range of remote meter reading system. Conventional radio often works at UHF frequency band, but if needed, it is used in the VHF frequency band as well.

$400 \mathrm{MHz}$ radio systems can access up to several RTU over a radius of $40 \mathrm{~km}$, if repeater is used. Similar $900 \mathrm{MHz}$ systems like $400 \mathrm{MHz}$ system can access multiple RTU but within the radius of $25 \mathrm{~km}$.

It has a favorable low price for data transmission of low speed.

\section{Equipment used in the transmitter}

- Radio transmitter set

- Antenna wire RG58

- VHF frequency antenna tube

- $7.2 \mathrm{AH}$ sealed acid batteries

- $5 \mathrm{~W}$ solar cells

- Rectifier diode

- Rig to install the antenna and solar cell protection 


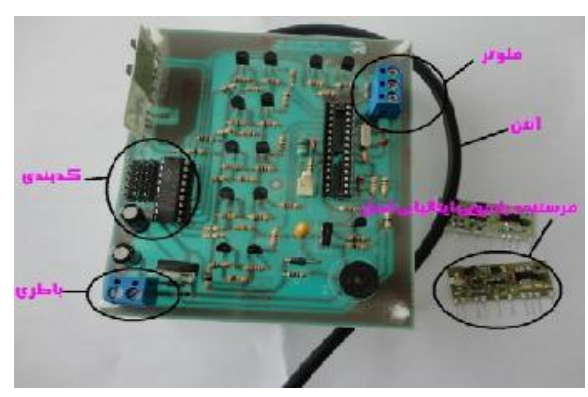

Fig.12.

Designed radio transmitter in licensed UHF frequency band station sends information in the frequency range of $433 \mathrm{MHz}$ to the receiver tank. This transmitter has features of 6-bit encoding that creates the possibility of using 64 transmitter and receiver in one area.

Antenna wire in the transmitter and receiver devices is one of the most important parameters that affect the transmitter and receiver benefit. The antenna used in the transmitter devices uses RG58standard. Moreover, complex telecommunication forms calculate the size of antenna tubes used.

The use of sealed acid batteries with a shelf life of 7 years and the use of high-quality stereo socket for connecting the transmitter

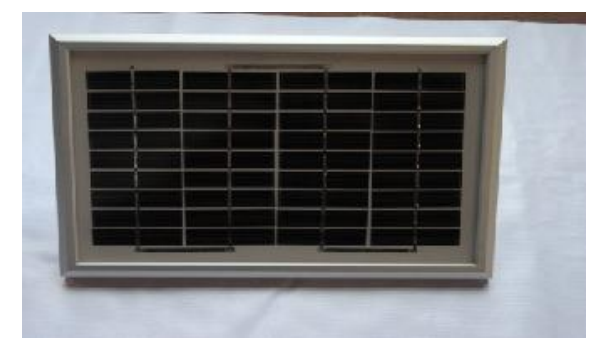

Fig.13. 5W Solar cell

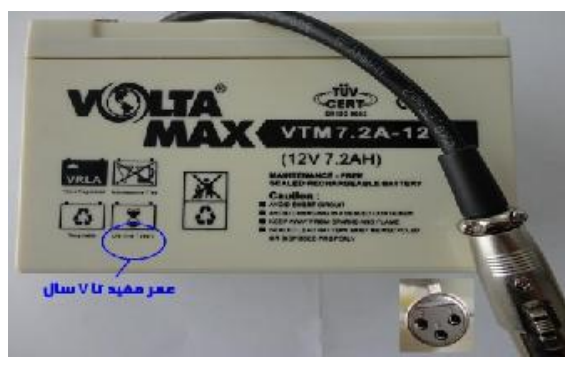

Fig.14. Solar batteries 
The output power of this cell is 5 watts, which considering 200 MW consumption of the transmitter in idle mode and $700 \mathrm{MW}$ in transmit mode (every 15 minutes), one can say that the battery saves up to 50 times the production of consumer.

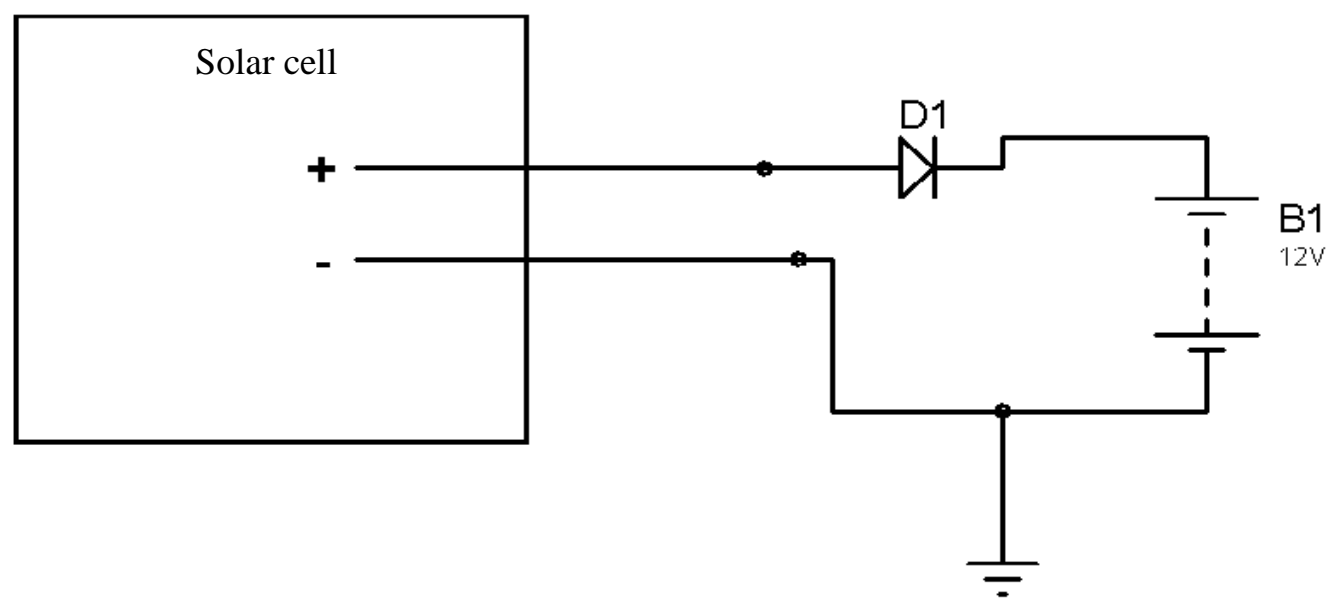

Fig.15. Connecting the solar cell to the battery

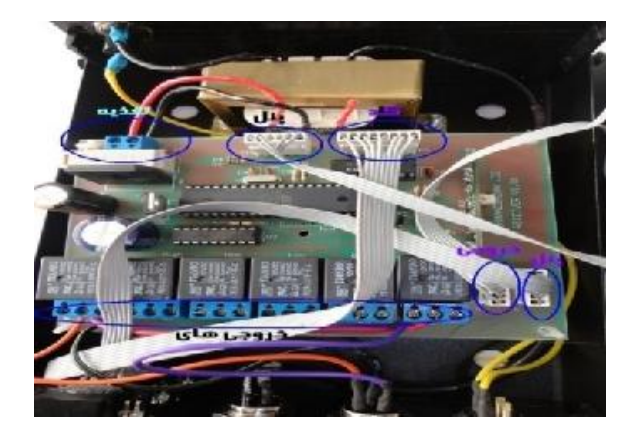

Fig.16. Radio receptor

To connect the solar cell to the battery, one must use a rectifier diode, which makes the cells not act as a consumer at night.

\section{Equipment used in the receiver}

- Radio receptor device

- Antennas and antenna wire with stand 
- Controllable outputs

- Water level displays

\section{GSM Monitoring Device}

Equipment used in devices

1. Transmitter of monitoring information

2. $900 \mathrm{MHZ}$ antenna

3. GSM device

4. Controllable outputs

5. Errors and information inputs

6. SIM

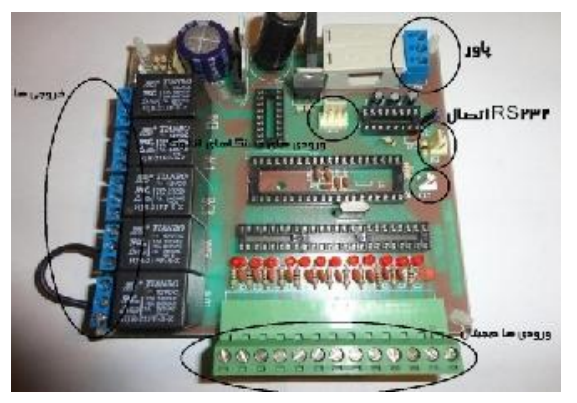

Fig.17. Transmitter of monitoring information

\section{CONCLUSION}

Conducting this project empowers water and wastewater companies in efficient use of resources, so that in this project once a sudden increase in consumption is spotted an alarm goes off in webbased software, announcing the possible fractures in transmission lines and prevents water loss and other damage and provides the ability to control and manage consumption. In this project, while remote reading the bulky mechanical meters; we could use solar energy to provide electricity requirements and infrastructure for telecommunication devices we used in data transmission. Similar digital systems only work with $220 \mathrm{~V}$ that, in practice, is not applicable for rural and remote areas where there is no access to electricity. Low price of mechanicalvolumetric meters compared to ultrasonic and magnetic ones, domestic production of these meters, and convenience after-sales service in supplying components, and acceptable accuracy are the distinguishes features of this device compared to the magnetic device. In addition, 
replacing these meters with similar ultrasonic and magnetic ones imposes heavy costs to water and wastewater companies, which is inaccessible according to their current budgets.

\section{REFERENCES}

[1] Barmeh Ziar, R., 2011, telemetric studies of wells and drinking water reservoirs-Avlyn International Conference Natrava-Civilica.

[2] Zappe R.W., valve selection Hand book $3^{\text {rd }}$ ed, Gulf pubilishing company Houston, Texas, 1971.

[3] Sanks, R. L., pumping station Design, Butter Worth - Heinemann, stoneham, Massachusetts, 1989.

[4] Clark, J.W., Viessman, W, JR, and Hammer, M.J, water supply and pollution control $2^{\text {nd }}$ ed., International Text book company, London, 1971.

[5] Industrial flow measurement, by David.W.Spitzer, published byISA, (America), 1990.

[6] Flow Measurement technique use, by Dr Y. L. Arora, published by Universal book corporation (India), 1978.

How to cite this article:

Barmeh Ziar R. Designing remote web-based mechanical-volumetric flow meter reading systems based on renewable energies. J. Fundam. Appl. Sci., 2016, 8(3S), 71-89. 